Mueller, Elizabeth J. and J. Rosie Tighe, (2007) "Making the case for Affordable Housing: Connecting Housing with Health and Education Outcomes." Journal of Planning Literature, vol 21, no.4: pp. 371-385. May 2007 (ISSN: 1552-6593) Published by SAGE DOI: $10.1177 / 0885412207299653$ The official version of this article can be found at: http://jpl.sagepub.com/cgi/content/abstract/21/4/371

Keywords: affordable housing

\title{
Making the Case for Affordable Housing: Connecting Housing with Health and Education Outcomes
}

\author{
Elizabeth J. Mueller and J. Rosie Tighe
}

\begin{abstract}
As advocates push for inclusion of affordable housing beyond the central city, siting battles have become increasingly common. Opponents often claim that affordable housing brings no net benefits to the community, and that it threatens neighborhood property values. This review considers existing evidence regarding the relationship between provision of quality affordable housing and benefits to the larger community. Evidence is considered in the areas of health and education. Given the high level of public concern with these two issues, evidence of benefits could be especially potent in public discussions of affordable housing. Future research is proposed in each area.
\end{abstract}

\begin{abstract}
ARTICLE
As advocates push for inclusion of affordable housing beyond the central city, "not-inmy-backyard" battles have become increasingly common. Opposition to affordable housing often rests on the assumption that affordable housing brings no net benefits to the community, and that it threatens property values in the neighborhood concerned. Planners are often caught in the middle of these battles, under pressure to satisfy existing neighborhood residents while also called by their code of ethics to work toward "social justice . . . recognizing a special responsibility to plan for the needs of the disadvantaged and to promote racial and economic integration" (AICP 2005). Both advocates and planners struggle to make the case for the broader community benefits of providing affordable housing to low-income residents. This article reviews the
\end{abstract}


evidence for the social benefits of affordable housing in two areas: health and education.

Not so long ago, improving housing was seen not only as a benefit to individual households, but integral to the health of the entire community. The field of city planning began, in part, because of concerns about the effects of poor housing conditions on the broader community. The urban reform movements of the nineteenth and early twentieth centuries are often cited as antecedents of city planning in the United States. Together, reformers united concern for the moral character and sanitary and physical well-being of the largely immigrant residents of tenement housing in newly industrial cities.

Progressive era workers embodied the connection between housing, health, and overall social well-being (Stivers 1995; Birch 1994; Davis 1967). The urban tenements of the early twentieth century were overcrowded, lacked basic services, and created fire and health risks for all of the city's inhabitants. Building codes, zoning ordinances, and fire safety requirements all stem from these early efforts to protect the health, safety, and welfare of the tenants themselves, as well as the greater metropolitan community (Tolnay, Adelman, and Crowder 2002).

In current terms, while planners still find themselves in the middle of battles over housing issues, the relationship between housing and larger social concerns is less apparent. As concern has shifted from poor housing conditions to the high cost of housing, and as housing has become increasingly viewed as an asset or investment, zoning and other planning tools have been used to preserve or enhance housing values for owners. In this context, where battles are increasingly taking place in middle-class neighborhoods, providing affordable housing to low-income residents is viewed more like a contagion than a social good (Massey and Denton 1993). While the legal "grant of power" to do zoning is described in standard enabling legislation as "for the purpose of promoting health, safety, morals, or the general welfare of the community ..." (Callies, Freilich, and Roberts 1999, 33) the tug-of-war between property rights and the general welfare at the local level is a mainstay of planning practice.

This review considers existing evidence regarding the relationship between provision of quality housing to low-income households and social benefits to the larger community. We have focused our search for evidence of social benefits on two policy areas: health and education. We chose these two areas both because they resonate with early motivations for housing reform and planning and because public concern over their rising public costs and poor outcomes is well established in each case. If stable, quality housing can be shown to produce positive outcomes in community health and education, and if neighborhood conditions also prove important to outcomes, planners may be able to make more effective arguments for the dispersion of affordable housing using this evidence. 
The connection between housing and health care costs is most visible-and most frequently discussed-for the homeless. In fact, in a few places around the country, initiatives to address homelessness are increasingly focusing on lowering health and social service costs by giving homeless people permanent housing. Other, more subtle, connections between housing and health are rarely discussed outside of health policy circles. Education represents the reverse case: the nexus between property values and school quality is well known and impedes efforts to site affordable housing. Since public education is most commonly funded primarily through residential property taxes, maintaining taxable property values is integral to the quality of the school system. And the relationship is reciprocal: studies have shown that the quality of the public school system is one of the leading factors in area home values (Kain and Quigley 1970; Li and Brown 1980). Given the high level of public concern with these two issues, evidence of benefits could be especially potent in public discussions of affordable housing.

In this review, we focus on several key questions. First, how well are the relationships between housing stability or housing conditions for low-income households and health and education outcomes established in the existing empirical literature? Second, have the specific conceptual mechanisms relating housing and health and/or education been laid out, and is there general agreement among researchers about their form? Finally, based on the evidence, how strong are these relationships? The article is organized into several sections. Following this introduction, we present a brief discussion of public perceptions of affordable housing, and the rationales for action or opposition that resonate most strongly with the public, based on existing polling data. The next two sections present our review of existing evidence of connections between access to decent, affordable housing and education and health outcomes. Finally, we conclude with an assessment of existing evidence and propose a strategy for moving forward.

\section{PUBLIC PERCEPTIONS OF AFFORDABLE HOUSING NEEDS, RATIONALES FOR ACTION}

To determine what is known about current public perceptions of affordable housing and arguments for supporting housing policies or projects, we reviewed six recent opinion polls that focused on housing issues (CAH 2002; Donahue Institute 2005). ${ }^{1}$ On the whole, recent polling demonstrates that housing is a second tier issue for most Americans, falling far behind education and health care on the list of important issues facing the country. Yet Americans generally agree that low-income families face serious housing problems and support statements that emphasize community obligations to provide housing for those in need. Most respondents express concern when presented with nation or their region to the problems of sympathetic groups, such as working families or children. For example, a national study sponsored by Fannie Mae Foundation found that participants responded most favorably to questions that emphasized fairness or assistance to families with children. A regional poll, conducted in Illinois, explored some of the same issues and came to similar conclusions (CAH 2004). 
Economic arguments for addressing housing needs resonate especially well. Poll respondents typically support general arguments about the link between housing affordability and the health of the regional economy (Housing Illinois 2003; Donahue Institute 2005; National Association of Realtors 2003). The public also sees an economic development payoff to this type of public spending: a National Low Income Housing Coalition poll found that 61 percent of respondents agreed that the economy would benefit from federal spending on affordable housing (CAH 2004, 32).

Three lessons emerge from the polling data. One is the abstract nature of the support for affordable housing expressed in these polls. Polls reviewed show support is highest for the most abstract statements-as well as for statements that reflect the respondent's own concerns or experience. As questions became more specific about local issues or policies, support typically declined. This trend is consistent with public opinion theory, which posits that public support is often stronger for abstract ideals and goals than concrete policies (Erickson and Tedin 2003).

The second lesson concerns the ease with which support can be shaped or manipulated by question wording. Many of the existing polls were designed to test different frames for housing by using different language, which evokes particular groups or types of likely benefits of programs. Support was strongest when questions emphasized the benefits of housing stability for children and for neighborhoods, or the self-help aspects of programs. It was weakest when respondents were asked specifically about affordable rental housing or about housing types other than single family. Discomfort with housing types other than single family may be another indication of opposition to rental housing.

The third lesson concerns race. While racial bias may lie behind opposition to affordable housing, it is difficult to discern from existing polling data. As in local siting battles, respondents are hesitant to mention race as a factor in their opposition. Yet racial overtones emerge from the groups respondents favor in their responses affordable housing. In their summary of polling data on attitudes toward affordable housing, the Campaign for Affordable Housing recommends that advocates "show that the people who will benefit directly include children, elderly people and working families-groups the public easily accepts as deserving" (CAH 2004, 7). The overlap between the categories "undeserving poor" and racial minorities is long established (Gilens 1999). When directly asked, respondents demonstrated little sympathy for racial discrimination as an obstacle to obtaining an affordable home (National Association of Realtors 2003).

Overall, support for affordable housing policy seems shallow and difficult to link to support for action or concrete programs. To date, the emphasis in polling and in discussions among housing advocates has been on understanding (and refuting) the claims most likely to fuel opposition. In this process, advocates have taken opponents' stated reasons for opposing housing at face value. As a result, discussion of the reasons behind opposition has remained at the scale of projects, households, and neighborhoods. Less attention has been focused on understanding the factors likely to 
increase support for local housing programs or projects. Yet there is no reason to limit the search for benefits to a similar scale. The benefits of housing assistance are unlikely to stop at the thresholds of the households receiving them.

There is reason to believe that the public can be moved by arguments about their shared interests in supporting public spending that most directly benefits others. Much attention has been focused on the social benefits of improving the health and education systems. Concern centers on the social costs of poorly performing systems. While those battling specific projects may not be moved by evidence that provision of affordable housing can improve local education and public health outcomes, decision makers and local tax payers footing the bill for schools and local health programs may view things differently.

\section{LINKING HOUSING STABILITY, QUALITY, AND LOCATION TO EDUCATIONAL OUTCOMES}

Increasingly, public policy favors dispersal of affordable housing options throughout the community through use of vouchers or by reducing concentration of poverty in buildings through mixed-income development strategies.

These policy shifts have been based on claims about the positive effects of giving lowincome people access to better schools and services in non-poor neighborhoods and of exposure to middle-class peers and social norms

(Galster and Killen 1995; Schwartz and Tajbakhsh 2001). This shift in policy responded to the findings of the vast literature on the "neighborhood effects" of living in a lowincome neighborhood. This literature, which blossomed after the early 1990s, has focused on identifying the structural dimensions of neighborhood disadvantage (Wilson 1987).

Many authors have documented the particular effects on children of living in high poverty neighborhoods (Jencks and Mayer 1990; Leventhal and Brooks-Gunn 2000; Sampson, Morenoff, and Earls 1999; Wikstrom and Loeber 2000; Small and Newman 2001; Coulton, Corbin, and Su 1999; Elliott et al. 1996; Brooks-Gunn, Duncan, and Aber 1997). In this section, we will consider research focused at two levels: At the first level, we review research that attempts to isolate the effect of housing stability or conditions on educational outcomes; at the second level, we review research that focuses on broader neighborhood characteristics and how these are related to educational outcomes. Numerous studies touch on the relationship between housing stability and education, but few do so explicitly. The main areas of focus throughout the literature include: the impact of student mobility on schools and student performance, the relationship between housing quality and academic performance, access to opportunity through quality public schools, and the financial impacts of new housing development on schools. Together these studies provide strong evidence of the positive relationship between housing quality and stability and educational outcomes at various levels. Yet, despite the volume of relevant research, it remains difficult to translate these findings 
into estimates of the positive impact that the provision of stable, quality housing could have on educational performance.

\section{A. Effects of Housing on Education}

\section{MOBILITY}

One result of an unstable or unaffordable housing situation is that low-income families are forced to move frequently to find adequate affordable housing. Many studies have examined the effects that frequent moves have on children's scholastic achievement, as well as the impact that increased student mobility has on classrooms and schools as a whole. In her review of studies on the mobility of poor students, Sheila Crowley addresses the housing problems that lead to mobility and the impacts on education. She states, "Families with housing problems are at high risk for forced mobility because housing that is overcrowded, in poor repair, or presents health hazards puts enormous stress on the residents. Housing that costs more than the household can afford threatens stability, exposing the household to the possibility of foreclosure or eviction" (Crowley 2003, 23). Furthermore, she finds that if moves are frequent, because of factors outside of the family's control, or if they do not significantly improve housing conditions, they will be detrimental to children (Crowley 2003, 23).

Longitudinal studies have tracked students who move often, and examined their academic achievement relative to those who remained in the same classroom over time. The United States has the highest household mobility of any developed country: according to the 2000 Census, between 15 and 18 percent of school-age children moved in the previous year (U.S. Census 2001.) A 1993 study by the U.S. General Accounting Office study found that one in six third-graders had attended three or more schools since entering first grade. The research indicated that the mobility of children is often a reflection of underlying family issues, particularly shortages of affordable housing (U.S. GAO 1994). Children who change schools often are exposed to curricula that vary greatly across schools and districts, forcing them to catch up and shift their focus to different material in the middle of the school year. Among third graders who attended three or more schools since first grade, 41 percent demonstrated belowaverage scores in reading compared with 26 percent of those who never changed schools; 33 percent of mobile students were below average in math, as opposed to 17 percent of stable children (U.S. GAO 1994, 6).

As a result of falling behind in reading and math, children who move frequently are more likely to repeat a grade than those who do not move frequently (U.S. GAO 1994). The U.S. GAO study also showed that increased mobility as a child has long-ranging consequences. Children who changed schools four or more times by eighth grade were at least four times more likely to drop out than those who remained in the same school (U.S. GAO 1994). The social and personal costs of dropping out are also high: dropouts are less likely to find jobs that pay well enough to keep them off public assistance. In 
2004, the unemployment rate for high school dropouts was more than double that for high school graduates (U.S. Department of Education 2004, Table 380). In an analysis of the social costs of high school dropouts in Los Angeles in the mid 1980s, Catteral estimated a lifetime loss of earnings of $\$ 3.2$ billion for the district's 20,000 dropouts. In addition, he estimated annual service costs for local governments in the region attributable to dropouts at $\$ 488$ million (both figures are in 1985 dollars). The bulk of the service costs were crime-related (Catteral 1987, 26-27).

The Kids Mobility Project performed a qualitative study of 100 families with a history of frequent moves. Many of the families reported "relentless and often futile searches for adequate, safe, and affordable housing" (Buerkle 1998, 1). Furthermore, when interviewed, parents expressed concern that frequent moves made it difficult for their children to adjust to new schools, friends, and neighbors. Stressful relocations resulted in frequent absenteeism, further exacerbating poor school performance and behavior. These statements were corroborated by reports from teachers indicating "poorer school attendance, school performance, and social and emotional adjustment for children with frequent moves" (Buerkle 1998, 1). Frequent moves also have long-term consequences for educational performance. Haveman et al. utilized longitudinal data from about 1300 students included in the University of Michigan Panel Study of Income Dynamics in their research on childhood events that impact high school completion (Haveman et al. 1991). This research included people who were over age four in 1968 and remained in the study in 1987, at which time the participants ranged from nineteen to twenty-three years old. Based on the percent of participants who the physical location of a young child (seven years or younger) or an adolescent (twelve to fifteen) "has a strong negative and significant effect on achievement" (Haveman et al. 1991, 144). Furthermore, moving one's residence as a child has a greater impact on high school graduation than poverty or welfare dependency per se. Mobility in early childhood also has lasting negative social and psychological effects. A longitudinal study that tracked 4,500 students in California and increased the risk of violent behavior in high school by 20\%" (Rumberger 2003, 8). Similarly, Buerkle's qualitative study found that "students from already-struggling families ... 'fall behind' academically and socially, forfeit social support systems and sometimes act out their feelings of loss in ways that further isolate them" (Buerkle 1998, 3).

A number of researchers have begun to delve into the influence household mobility has on the peers of children in these situations. Determining classroom effects is necessary to fully understand the extent that a lack of decent and affordable housing has on other policies, particularly in education. Hartman and Franke $(2003,1)$ note: "The major education reforms put forward-smaller classes and schools, lower teacher/ student ratios, better-trained teachers, improved physical plant and facilities, the increased emphasis on testing and accountability, etc.-all are seriously undermined, if not made irrelevant, if the classroom is a revolving door."

By having to catch up or change curricula, mobile students take time and resources away from other students in the classroom, increasing the strain on teachers and school systems: "The stable classmates of to constantly double back to integrate new students 
into the classroom lose precious time on lessons for the whole class and have less time for all students individually" (Crowley 2003, 2).

While the above studies support the connection between residential mobility and educational outcomes, they have been criticized by some for overstating the connection. Studies that controlled for the various characteristics of students who moved found that the impact of mobility on outcomes diminished. A study of mobile students in Chicago found that half of the difference in achievement between movers and non-movers was because of differences between students that pre-dated their school changes (Temple and Reynolds 1997). A study in Baltimore found that the negative associations between changing elementary school and test scores, grades, retention, and referral to special education were mostly insignificant once family characteristics and academic performance in the first grade were added (Alexander, Entwisle, and Dauber 1996). Based on these findings, researchers argue that students who move are more likely to be poor and low performing before they move (Nelson, Simoni, and Adelman 1996). How these poor students would have done if they had remained in one school cannot be determined from existing studies. That comparison remains to be made.

Studies that controlled for demographic characteristics but not prior academic performance found that movement was strongly linked to poor academic performance. Using data from a national health survey, researchers found that frequent (three or more) moves predicted grade retention (Simpson and Fowler 1994; Wood et al. 1993). Tucker, Marx, and Long (1998) found that for children in single parent households even one move could have a negative impact on their combined measure of academic and behavioral performance at school.

The connection between changing schools and high school graduation remains strong even after controlling for family characteristics (Haveman and Wolfe 1994). Several studies drawing on a national database of 10,000 high school students found that changing schools between first and eighth grade increased the odds of dropping out even after controlling for family characteristics and prior academic achievement (Rumberger and Larson 1998; Swanson and Schneider 1999; Teachman, Paasch, and Carver 1996).

\section{HOUSING QUALITY AND ACADEMIC PERFORMANCE}

Housing conditions have the potential to strongly affect a child's ability to perform academically and adapt socially. The main areas of concern here are overcrowding, inadequate heat or plumbing, infestation by rodents, and neighborhood conditions. Braconi (2001) found that cramped or inadequate study areas impede the ability of school-age children to complete homework. The New York based Citizens and Planning Council conducted a study of some 4,000 residents between the ages of nineteen and twenty-two, using the city's Housing and Vacancy Survey. Their results showed a significant relationship between crowded housing situations and reduced 
rates of high school graduation. Crowding reduced the probability of completing high school by 11 percent in males, and 6 percent in females. The researchers conclude that poor quality housing negatively influences a child's ability to focus at school, increasing stress and causing poor health or attendance that leads to poor academic performance (Braconi 2001, 1). Together, this research supports claims that poor housing conditions can create poor study environments that reduce learning.

\section{HOUSING AND SCHOOL COSTS}

One oft-expressed fear relating to affordable housing development is that the new housing will create a burden on a community's school system by bringing large numbers of new students into already overcrowded schools. While claims abound, few studies systematically examine this issue. The few that do find that new housing, especially new affordable housing, has much less of an impact on municipal school costs than anticipated. A Massachusetts study of forty-one developments around the state found that most developers significantly overestimated the number of children that would be added to the community, leading to exaggerated cost estimates (Sanborn et al. 2003). A second study that surveyed affordable housing constructed under the Low Income Housing Tax Credit program in Ohio found that households in these projects had, on average, the same number of children as unsubsidized apartment dwellers. However, when disaggregated further, subsided units were found to have more preschoolers than market rate units (Danter Company 2001).

Senior citizens, whose consistently higher voter turnout can sway local elections, are thought to be particularly sensitive to arguments about school costs (Burton 1992). Indeed, several studies have found that communities with a higher share of elderly residents are more likely to spend less on schools (Poterba 1997; Inman 1978). However, more finely grained studies that are able to disaggregate the elderly population and assess their preferences individually do not support such blanket conclusions. Using contingent valuation survey methods, paired with a post election survey of seniors voting in a local school budget referendum, Duncombe, Robbins, and Stonecash (2003) found that seniors preferences' for school spending did not move uniformly and did not differ systematically from those of non-seniors.

\section{ACCESS TO EDUCATIONAL OPPORTUNITY}

Evidence of the impact that neighborhood conditions have on educational outcomes comes from a handful of policy initiatives aimed at helping low income residents of high poverty neighborhoods move to low poverty and/or low minority neighborhoods. The earliest programs were the result of antidiscrimination litigation; thirteen such programs were in operation in 2000 (Schwartz 2006, 166). The best known and most influential program is Chicago's Gautreaux program, established in 1976 as the result of a lawsuit against HUD and the Chicago Housing Authority for past discrimination and segregation in public and subsidized housing. The program offered those on waiting lists or currently 
residing in public housing the chance to receive vouchers and counseling to help them move to predominantly white neighborhoods in the metropolitan area (Schwartz 2006, 167).

Studies of Gautreaux and other mobility programs conclude that the location of housing and schools in dangerous neighborhoods can impact a child's attitudes toward school (Rosenbaum 1991; Rosenbaum and DeLuca 2000; Duncan and Ludwig 2000; Goering et al. 1999; Young 2001). Housing in noisy buildings and areas, or overcrowded situations, can lead to broken sleep and an inability to have quiet study time, as well as increased absences (Young 2001). In contrast, housing options in communities with greater resources allow low-income children access to better schools. Deconcentrated to take more honors and Advanced Placement courses and gives them greater access to extracurricular activities and smaller, more stable classes (Quercia and Bates 2002; Rosenbaum 1991; Rosenbaum and DeLuca 2000). So researchers have established that educational opportunities improve-but do outcomes?

Rosenbaum, in a series of studies, compared educational achievement outcomes for those moving to the suburbs through the Gautreaux program with those remaining within Chicago (Kaufman and Rosenbaum 1992; Rosenbaum 1995; Rubinowitz and Rosenbaum 2000; Rosenbaum, Kulieke, and Rubinowitz 1988; Rosenbaum et al. 1991). His findings were dramatic. Rosenbaum's 1988 study reported that children moving to predominantly white suburbs were significantly less likely to drop out of school (5 percent vs. 20 percent of those moving within Chicago), more often in college track courses (40 percent vs. 24 percent), and more likely to enroll in four year colleges (27 percent vs. 4 percent) (Rosenbaum 1995, 242-4).

Methodological problems have cast doubt on findings from the Gautreaux program. Studies were based on small samples of program participants who were not randomly selected. Research focused on participants who had remained in the suburbs, since those who did used to screen residents, and the persistence required to enter the program, make participants difficult to compare to non-participants (Popkin et al. 2000).

The other important source of evidence on the relationship between neighborhood conditions and improvements in education and health outcomes for low-income residents is the evaluation literature on the federal Moving to Opportunity for Fair Housing (MTO) program. MTO was designed explicitly as a social experiment to facilitate evaluation of the impact that improved neighborhood conditions had on the lives of former public housing residents. The design of the program differed in important ways from Gautreaux movers did not all go to non-minority suburbs, some relocated to minority city neighborhoods. In contrast to the findings of the Gautreaux evaluations, interim evaluation research on the results of the MTO program have found little evidence linking neighborhood conditions to better educational performance. Program participation had small but significant effects on the characteristics of schools attended and did result in a large drop in the yielded no significant effects on measures of educational performance (Goering 2003, 143; Orr et al. 2003). Longer term effects await the program's final evaluation. 


\section{B. Summary}

Current empirical literature provides evidence of a strong, negative relationship between frequent residential mobility and educational performance. Evidence also suggests that poor housing conditions impede educational performance, although the magnitude of this impact is not well quantified. In both cases it remains difficult to quantify the social cost of these impacts in ways meaningful to the public. In addition, evidence is lacking of the positive impact on educational performance, or cost savings to schools or society, that might be achieved by reducing mobility or improving housing conditions. In particular, this type of evidence is not available for how improvements in the stability of living conditions of low-income children or families would impact educational performance. Without this type of information it is hard to make straight forward arguments about the social benefits in the area of education that access to quality affordable housing could yield.

Based on these findings, housing stability is clearly of great importance to educational performance-for the students that move, for their peers in the classroom, and for school districts where they live. Impacts are most easily measured and quantified at the individual level. While the studies provide evidence of the strength of difficult to translate them into estimates of the positive impact that housing stability might have on educational performance for several reasons. First, as noted above, differences in socioeconomic status may be responsible for some of the differences in performance. Thus, students who do not move often may be performing better, in part, because of their class background. To determine what the benefit might be of providing stable quality housing to low-income households, we would need to compare the performance of low-income children who moved and who did not.

In addition, while the literature remains limited on the connection between neighborhood conditions and educational outcomes, past evidence of the relationship between neighborhood conditions and disadvantage provide a strong basis for incorporating the neighborhood level into future research. The Gautreaux and MTO initiatives were designed to steer movers to nonpoor neighborhoods. They did not purposely vary factors more directly tied to education, such as measures of school quality or educational performance by neighborhood. Future research on mobility should take these factors into account.

\section{A Strategy for Connecting Housing Stability and Education}

We propose that researchers focus on studies that establish the connection between housing stability and educational outcomes and, subsequently, to social costs associated with these connections. To do so, these studies must provide a basis for assessing the impact of improving housing stability for low-income students, controlling for their academic performance level at the start of the study. Researchers must create 
a basis for comparison by looking at elementary children from similar backgrounds who did and did not move in the same area, where movement was because of housing instability (rather than choice, better schools, etc.), and tracking educational outcomes through high school. An ideal situation for such a study might be tracking children at an elementary school that draws students from both a nonprofit affordable housing development and from private, more costly apartments. Study subjects could be chosen to be as similar as possible in terms of educational performance, with help from the school counselor at the elementary school. Research methods would include qualitative research, to track the various ways that differences in household stability impact school performance, as well as quantitative measures of school performance, such as grades and test scores. An alternative approach would be to begin with families with school age children on the waiting list for housing vouchers. Researchers could create comparison groups of those who did and did not receive vouchers, controlling again for household income and starting educational performance. It would be particularly important to ensure that moves were not between schools or neighborhoods of dramatically varying character or quality.

\section{LINKING HOUSING CONDITIONS AND HEALTH OUTCOMES}

The relationship between housing and health has been studied in both the public health and housing literatures. Housing researchers focus on the impact that high housing costs have on the quality of health care residents can access. Public health researchers focus on the health problems associated with particular housing conditions, or with particular neighborhood environments. In this section, we review the evidence from both perspectives. Housing researchers are beginning to include indicators of health in studies of the impact of shortage of affordable housing on low-income families. Researchers include health outcomes among the possible impacts of high housing costs for working families. These studies focus on the trade-offs households make as they compensate for relatively high housing costs. A recent report by the Center for Housing Policy (CHP) found that children in poor families paying more than half their income for housing were more likely to have fair or poor health than children in poor families with lower housing costs (Lipman 2005, 9). Households appear to be forgoing health insurance to meet their housing costs: a study of households without health insurance in the 1990s that found that lack of insurance was linked to high housing costs (Levy and DeLeire 2003).

Overall, households with children appear to be under the greatest stress: the CHP report notes that low income families with children paying more than half their income for housing were more likely to experience "food insecurity" 2 or to have a family member without health insurance in the previous year than similar families without children (Lipman 2005, 32). A separate study of children in five states found that infants and toddlers in households that are "food insecure" were 30 percent more likely to be hospitalized for illnesses and 90 percent more likely to be generally in fair or poor health than children that had adequate food at home. These children are more likely to develop learning disorders, emotional problems, and behavior problems at school. Underscoring 
the importance of housing costs in household budgets, the same study noted that families receiving housing assistance are better protected Sentinel Nutrition Program 2004 in CHP, 33).

Health researchers have studied the connections between housing and health at two levels: first are studies that seek to isolate particular features of individual homes that lead to health problems; second are those studies focusing on the connections between neighborhood level conditions and health problems. We review both types of literature here. Health researchers are developing their own "neighborhood effects" literature to explain racial disparities in health. The connection between socioeconomic status and health is well established (House et al. 1990; Link and Phelan 1995; Williams 1990) and is argued to lie behind racial health disparities (Williams 1997). Recent research has identified segregation as a determinant of differences in socioeconomic status, thus adding another dimension to the neighborhood conditions discussion (Williams 1997; Williams and Jackson 2005).

\section{A. Physical Health Problems}

Public health researchers have documented many connections between conditions in low socioeconomic status neighborhoods and various health concerns. Neighborhood effects have been established for low socioeconomic status neighborhoods, independent of individual level risk factors, for intentional injury (Sampson, Raudenbusch, and Earls 1997; Cubbin, LeClere, and Smith 2000); poor birth outcomes (Pearl, Braverman, and Abrams 2001); cardiovascular disease (Diez Roux et al. 2001); tuberculosis (Barr et al. 2001); depression (Schulz et al. 2000); and mortality—from whatever cause (Bosma et al. 2001).

Safety lies behind many of these differences. It influences exposure to violence and influences access to health care and likelihood that trauma victims will receive timely care, affecting homicide rates. Residents' perception of local safety also influences their physical activity. A 1999 CDC report found that residents who "perceive their neighborhood to be unsafe were more likely to be physically inactive" (196). Cohen et al. (2003) used boarded-up houses as a proxy for poor neighborhood conditions and found it positively linked to rates of gonorrhea and premature death in their study of 107 U.S. cities, after controlling for race, poverty, education, population change, and health insurance coverage. The authors concluded that such conditions may have an adverse effect on social relationships and limit chances to engage in healthful behaviors. A multilevel longitudinal study of families and communities in Chicago examined data on youth ages eleven to sixteen and caregivers in eighty neighborhood clusters. They found that physical activity, measured by hours spent in recreational programming, was significantly likely to be lower in neighborhoods residents assessed to have low levels of safety and high levels of social disorder, controlling for demographics (Molnar et al. 2003). 
Evidence from studies of residents of dilapidated public housing supports the importance of both housing and neighborhood conditions for residents' health. Public housing designated for redevelopment under the federal HOPE VI program includes some of the poorest quality public housing in the country. Researchers compared the health status of residents of this housing (before redevelopment) to residents of other publicly assisted housing across the country, to other people living below the federal poverty level and to non-poor people. They found that both residents' perceived overall health status and their rate of medically diagnosed asthma was significantly worse than that of residents of assisted housing and of other poor people, despite their similar levels of economic deprivation (Howell, Harris, and Popkin 2005). To date, however, it remains difficult to specify the relationship between neighborhood characteristics and health outcomes since there is a lack of theoretical consensus about these connections, resulting in considerable methodological diversity across studies (O'Campo 2003; Humpel, Owen, and Leslie 2002.)

The connection between the condition of individual dwellings and resident's health is more clearly understood. According to one research review, "a substantial body of literature demonstrates that poor housing can contribute to infectious disease transmission, injuries, asthma symptoms, lead poisoning, and mental health problems" (Saegart 2003, 1471). Poor housing creates numerous health problems-especially in children. The connection between poor housing and poor health is considered so well established as to be "unarguable" (Thompson, Petticrew, and Morrison 2001, 261). Numerous studies have demonstrated that problems stemming from lead paint (Brown et al. 2001; Dunn 2000; Schultz et al.1999); poor air quality (Sharfstein et al. 2001; Quercia and Bates 2002); and fire and injury hazards (Shaw 2000; Mallonee et al.1996; Plautz et al. 1996) significantly inhibit the health and safety of residents.

Studies have considered the impact that poor housing conditions such as lead paint, mold, and fire hazards have on health, as well as the connections between poor housing, family well-being, and significant mental distress. In a review of evidence of the connection between housing conditions and health, James Dunn notes that health problems created by poor housing are indicative of social inequalities, which "persist over time and space, no matter how social status and health status are measured" (Dunn 2000, 344). Dunn connects the fields of housing and health from a population health standpoint, encouraging new research that incorporates housing as a significant factor in explaining numerous health indicators. From this perspective, "the medical care inputs and health behaviors (smoking, diet, exercise, etc.) but rather social and economic characteristics of individuals and populations" (Dunn 2000, 342). As one of the most important of these social and economic factors, housing is extremely important in determining the health of residents.

A significant longitudinal study conducted by Marsh et al. tracked nearly 17,000 residents of Great Britain over thirty years. The researchers developed a composite index of poor housing, comprised of measures of crowding, substandard facilities, and residential satisfaction. This index of housing deprivation was then used to explain residents' scores on a composite index of ill health. The findings strongly indicate that 
"housing deprivation has a substantial impact upon the risk of severe ill health" (Marsh et al. 2000, 424).

Furthermore, living in poor housing conditions as a child has long-lasting effects. As Marsh et al. found, residence in poor housing — whether in the past or currently — puts residents at greater risk of ill health. Even for those adequately housed as adults, ill health is more likely if they experienced housing deprivation in earlier life. Furthermore, respondents found to live in poor housing conditions in more than one survey period ran a ". . . 25 percent greater risk of disability (on average) or severe ill health across [their] life course" (Marsh

\section{LEAD PAINT AND INDOOR AIR QUALITY}

Lead poisoning is one of the most well-known and well documented health problems found in the home. Despite policies aimed at identifying potential lead based paint problems, as well as requirements for mitigation in many states, thousands of children suffer from lead poisoning every year. The Centers for Disease Control estimated that approximately one million children between ages one and five have elevated blood lead levels. An estimated 14 million children age six or under live in housing constructed prior to 1960; lead paint contamination is concentrated among units of this vintage (CDC 1997). Overall, twenty million homes are estimated to contain lead paint hazards; 3.6 million children live in such units (Quercia and Bates 2002, 2). Poor and minority children are disproportionately affected (CDC 1997).

Another major problem in substandard housing is poor air quality as a result of mold, pest infestation, and other toxins. Two studies-one in Britain and another in Canadafound that increased mold spore counts in the home were directly related to sickness, including respiratory and digestive sickness. Furthermore, these results held true after the impact of other environmental allergens had been taken into account (Hopton and Hunt 1996). Furthermore, asthma has been linked to poor indoor air quality. According to the National Institutes for Allergy and Infectious Disease, there are nearly 500,000 hospitalizations because of asthma each year, costing the U. S. economy over $\$ 10$ billion in direct health costs and lost work days. Studies have shown that poorly maintained housing and neighborhoods with excessive air pollution can cause or exacerbate Bates 2002). Cockroach infestation, a ubiquitous problem in many buildings, has been linked to asthma. According to one study, "10,000 children between the ages of 4 and 9 are hospitalized for asthma attacks each year because of cockroach infestation at home" (Shaw 2000, 3). Researchers have also linked asthma to dust mites in old carpeting (Platt-Mills et al. 1992), inadequate heat or hot water (Evans 1992), and crowding (Weitzman et al. 1990).

\section{SAFETY AND FIRE ISSUES}


The lack of adequate safety features in substandard housing contributes to numerous health problems and injuries, especially in children (Matte and Jacobs 2000). Many of these injuries, particularly scalding burns and other fire-related injuries, are a result of faulty heating systems and wiring that is not up to code. One longitudinal study of nearly 1,000 dwellings in Britain addressed the effects of adequate heat on healthparticularly the health of children. The study found that when units did not have included heat in the rent, reporting of headaches, poor appetite, aches and pains, sore throat, persistent cough, tiredness, and temper tantrums were significantly higher than in those that included heat (Hopton and Hunt 1996, 10-14).

\section{MENTAL HEALTH PROBLEMS}

Mental problems stemming from poor quality housing and financially burdensome housing can be significant for residents. Studies have found that poor quality housing can cause psychological stress (Kearns and Smith 1993; Dunn 2000) and can negatively impact self-esteem and family self-sufficiency (Evans et al. 2000; Bratt 2002; Shlay 1993). Some of the factors contributing to these mental issues include "anxiety about structural hazards, worry and lack of control over maintenance and management practices, and fear of crime" (Evans et al. 2000, 409).

\section{STRESS}

Problems stemming from housing affordability, poor building management, or health and safety issues create significant stress for residents, permeating every aspect of their daily lives. As one researcher noted, "housing stressors are significantly associated with psychological distress . . . living in a substandard dwelling represents an independent and added source of stress to the lives of people with lower incomes" (Kearns and Smith 1993, 610). A mixed method study of women living in low-income Detroit neighborhoods found that concerns about safety were significantly related to symptoms of depression, controlling for other sources of stress and for age, education, and income (Schulz et al. 2000). Echoing the results cited above, HOPE VI researchers also found that rates of stress-related mental illness were 50 percent higher than the national average among residents of dilapidated public housing. In addition, one in six reported having experienced a major depressive episode in the past year. Qualitative evidence suggested these results were the product of the tremendous stress of living in high crime neighborhoods (Popkin et al. 2004).

A particularly significant factor in housing-related stress is overcrowding. When families do not have sufficient space, activities in the home-including meals, homework, and play-become significantly constrained. As a result, researchers have found that crowding has significant psychological impacts- especially on families with children (Evans et al. 2000, 491). Evans found that parental anxiety over safe play areas, children's well-being, and maintenance concerns cause significant stress for parents and children. Many of these issues are associated with apartment living or public 
housing living, where constrained inside space and insufficient or dangerous outside space compounds these crowding issues.

The quality of rental housing management can also contribute to stress. Evans et al. found that housing owned by absentee landlords or managed by government agencies can cause stress for tenants who must wait for repairs, or navigate difficult bureaucratic processes to file complaints or achieve results (Evans et al. 2000, 492). Concerns about safety, heat, and hygiene create anxiety and worry because there is little predictability in the response time or the level of repair that will be received (Evans et al. 2000, 492). Furthermore, this contributes to an actual or perceived lack of control over the home environment, which should be a place where people should feel comfortable and secure (Bratt 2002, 13-15). At the neighborhood level, MTO evaluators found demonstrated improvements in stress and other psychological factors in families who moved to the suburbs over families who stayed in public housing or were relocated to similarly lowincome neighborhoods (Katz, Kling, and Liebman 2001; Rosenbaum and DeLuca 2000).

\section{SELF-ESTEEM}

Rachel Bratt's review of studies of housing and family well-being identifies various aspects of housing that can drastically influence the family, and how "improved housing conditions and less onerous housing cost burdens promote healthier, more productive families" (Bratt 2002, 14). The quality and perceived quality of one's housing greatly affects one's sense of self: housing in America is usually a family's greatest asset, and can be a great source of pride. As Marcus writes, ". . . throughout our lives, whether we are conscious of it or not, our home and its contents are very potent statements about who we are. In particular, they represent symbols of our ego selves" (Marcus 1995, in Bratt 2002, 19). Poor quality housing, especially public housing, can be a great source of shame for many residents.

\section{Summary}

Existing empirical evidence provides clear conceptual links between housing conditions and health problems. The strongest evidence comes from public health research, where specific connections between housing problems such as lead paint, cockroach infestations, and other factors are linked to specific illnesses and injuries. The evidence is most compelling and the effects most easily understood for children. Recent studies focusing on how high housing costs lead to poor conditions and thus to poor health, or to family budget trade-offs that shortchange health care, are starting to make the connection between housing and health status. More needs to be done to reinforce these findings and build confidence in the methodology behind them.

While substandard housing contributes to health problems, the impacts of improvements are hard to discern in existing studies where numerous factors in addition 
to housing conditions are considered and changes are multifaceted. Hopton and Hunt found that "studies of re-housing have found the consequences to be undramatic in terms of health, either physical or mental, since gains in satisfaction with housing tend to be offset by adversely perceived changes in social networks and social support" (Hopton and Hunt 1996, 15). In the MTO evaluation, one of the discernable benefits to residents moving to low poverty neighborhoods was increased safety-yet improved neighborhood conditions were not directly linked to improvements in health (Orr et al. 2003; Goering 2003).

Existing research documents the negative impact that poor housing or neighborhood conditions, lack of control over conditions, or lack of certainty regarding future housing options can have on various aspects of mental health. Conditions are measured at both the level of the individual dwelling and the neighborhood. Studies that examined the effect of improvements in housing conditions studied cases where conditions in units, in management, and in neighborhood conditions all changed simultaneously, making it hard to determine the relative importance of each factor in improvements in indicators of mental health.

The greatest difficulty comes in attaching social costs to poor conditions. Yet this is a critical step in making compelling arguments about the importance of housing problems. Aggregate measures of the cumulative loss of IQ points, of children "at risk" of various problems, or the magnitude of stunted growth or childhood illness are hard to translate into costs that make sense to the public. More compelling might be studies of differences in housing conditions between similar groups in the same community, and of measured differences in their use of local health services or other concrete local short term costs. Concrete local comparisons are likely to have the greatest impact-while also being the hardest to carry out methodologically.

\section{A Strategy for Connecting Housing Costs and Conditions to Health}

Many studies document the ill effects of poor housing on health, yet few focus on the potential impact of improvements on health outcomes and, subsequently, on costs. Existing work has provided a start but has not successfully separated housing conditions from other factors and looked at health outcomes specifically.

What is needed is a study that focuses on the health impacts of changes in housing conditions, all else equal, for low-income households with similar health profiles. Again, a comparison that tracks low-income households who do and do not change their housing conditions, and tracks similar types of local health costs would be most useful. One approach would be to use applicant lists for two types of services to pull together three groups, sharing similar general demographics and health characteristics for comparison: 1) households whose homes underwent specific types of rehabilitation; 2) households who moved into quality affordable housing units in different neighborhoods; and 3) a control group of households drawn from those remaining on either waiting list. If information is gathered from all households while they are still on the waitlist (or 
compiled retroactively), this would allow for before and after comparisons as well as cross group comparisons to be made. It would be especially important to ensure that households studied are similar in terms of their health problems and in the quality of health facilities available to them.

\section{CONCLUSIONS}

Part of the reason that subsidized housing does not resonate with Americans is that housing is a good that contains multiple layers of meaning to different people. At its most basic level, it is shelter: adequate housing prevents health problems as it protects residents from the heat or cold; poor housing can also foster poor health when it contains lead paint, asbestos, or vermin. The home is also the primary environment for child-rearing: affordable housing provides a stable environment for the raising of children, making it easier for them to attend a single school system, therefore providing continuity to their education. A stable home environment reduces stress on all family members, while financially burdensome or overcrowded housing in need of repair tends to increase stress. Furthermore, housing is property: the home is the largest investment for most families, and protection of this investment often includes opposition to anything that might decrease property values. Lastly, housing is also an important industry: housing construction, sale, lending, and repair make up a huge part of the U. S. economy, and housing stats are one of the leading indicators of economic strength.

Because housing is so multifaceted, it becomes a complicated issue in the minds of the American people. Support for government programs that provide housing or opposition to the development of housing in one's neighborhood are inexorably tied with one's view of the purpose of housing. This is not the case with other social issues-such as health care or education - that are more defined in the minds of Americans.

We began this exercise by describing the current context for housing battles in communities around the country: opponents are charging that there is no reason that they should consider accepting these developments; they see no benefits to them or to the larger community that justify them. We reviewed literature from two areas of research where the connections between housing and social costs seemed most likely to be documented and more easily translated into understandable costs for public discussion. Our task was to discern how far this evidence would take us: can we make strong claims about the social benefits of providing stable, decent affordable housing on the basis of existing research on the connections between housing stability and conditions and education and health outcomes? Where is support strongest (or weakest) for such claims? And where do we need more or more rigorous research to gauge the impacts?

Current empirical literature has begun to outline the ways that neighborhood conditions in low-income neighborhoods affect residents' socioeconomic and health status. To the extent that housing policy focuses on giving residents access to non-poor neighborhoods, these effects are especially important to understand. However, 
theorizing about these connections remains at an exploratory stage, with little agreement on the specific mechanisms that produce better or worse outcomes. Studies range in how they approach the issue, variables they identify as important, and measures used to track them. Neighborhood studies introduce multiple levels of analysis, raising the methodological complexity of such research. Nonetheless, future research on housing stability and education or on housing conditions and health would need, at minimum, to take neighborhood setting into account. In effect, neighborhood conditions provide the baseline for measures of change. Neighborhoods may determine school quality and effective access to emergency health services, for example. Any improvements in housing would need to be compared to changes that might have resulted from changes at the neighborhood level.

Existing research has established the conceptual connections to look for and, in some cases, strong evidence of a connection. Yet evidence is not focused clearly on the connection between the housing mobility of low-income households unable to pay rising rents, or living in poor conditions, and educational outcomes. The research also does not focus on the costs generated by the housing-related mobility of low income children in particular. While findings point to the importance of household income and other household characteristics in explaining educational outcomes for children who move, they do not give us enough information to make an argument about the difference in educational outcomes for poor children who do and don't move and the social costs of these differences. We need further research that focuses on that particular connection, its magnitude and the costs to the community of not acting.

What about the connections between housing conditions and health problems? Again, the evidence provides clear conceptual links between housing conditions and health problems. The strongest evidence comes from public health research, where specific connections between housing problems such as lead paint, cockroach infestations, and other factors are linked to specific illnesses and injuries. The evidence is most compelling and the effects most easily understood for children. Recent studies focusing on how high housing costs lead to poor conditions and thus to poor health, or to cost trade-offs that shortchange health care, are starting to make the connection between housing and health status. More needs to be done to reinforce these findings and build confidence in the methodology behind them.

Attaching meaningful social costs to poor conditions remains elusive. Aggregate measures used in the empirical literature are hard to translate into costs that make sense to the public. More compelling might be studies of differences in housing conditions between similar groups in the same community, and of measured differences in their use of local health services or other concrete, short term, local costs.

In both proposed studies, the biggest challenge would be to translate identified differences in school performance or health outcomes into social costs. The government bearing these costs, are likely to vary from place to place, further complicating the process. Perhaps the best approach would be to start with a fairly narrowly focused approach, by looking at costs that are clearly born by local government and most 
directly identifiable to local taxpayers as costs they bear for services with which they are familiar. This might mean, for example, specific costs to school districts generated by mobile students and costs for various sorts of staff or services. For health, this might mean costs for treating specific health conditions most directly related to poor housing conditions among people with similar levels of access to ongoing wellness care. Specific costs to track could be identified in consultation with local health care professionals familiar with the health care needs of low-income households.

Such studies, while ambitious and methodologically complicated, could produce results that are legible to members of the local community: higher school costs for particular functions or lost funds because of mobility-related poor performance, costs for addressing particular housing-linked health care needs important to overall public health. With this information, it might be possible to make a meaningful case for the benefit of affordable housing to the larger community where it is located.

\section{NOTES}

1. The polls covered were sponsored by the Fannie Mae Foundation, the National Low Income Housing Coalition, the National Association of Realtors, Housing Illinois, Vermont Housing Awareness Coalition, and the Citizen's Housing and Planning Association.

2. A family experiences food insecurity when it either runs out of food, cuts down the size of meals, or skips meals because of lack of money for food.

\section{REFERENCES}

Alexander, K. L., D. R. Entwisle, and S. L. Dauber. 1996. Children in motion: School transfers and elementary school performance. Journal of Educational Research 90 (1): 3-12.

American Institute of Certified Planners. 2005. AICP code of ethics and professional conduct. http://www.planning.org/ethics/ conduct.html (accessed January 9, 2007).

Barr, R. G., A. V. Diez-Roux, C. A. Knirsch, and A. Pablos-Mendez. 2001. Neighborhood poverty and the resurgence of tuberculosis in New York City, 1984-1992. American Journal of Public Health 91:1487-1493. 
Birch, E. 1994. From civic worker to city planner: Women and planning, 1890-1980. In The American planner: Biographies and recollections, 2nd ed., ed. D. Krueckeberg, 469-506. New York: Methuen.

Bosma, H., H. D. van de Mheen, G. J. J. M. Borsboom, and J. P. Makenbach. 2001. Neighborhood socioeconomic status and allcause mortality. American Journal of Epidemiology 153 (4): 363-371.

Braconi, F. 2001. Housing and schooling. The Urban Prospect 7: 1-4.

Bratt, R. 2002. Housing and family well-being. Housing Studies 17 (1): 13-26.

Brooks-Gunn, J., G. J. Duncan, and J. L. Aber, eds. 1997. Neighborhood poverty: Context and consequences for children, Vol. 1. New York, NY: Russell Sage Foundation.

Brown, M. J., J. Gardner, J. Sargent, K. Swartz, H. Hu, and R. Timperi. 2001. The effectiveness of housing policies in reducing children's lead exposure. American Journal of Public Health 91.

Buerkle, K. M. 1998. Report on kids and housing mobility. Minneapolis: Family Housing Foundation. http://www.fhfund.org/_dnld/ reports/kids.pdf (accessed July 18, 2006).

Burton, J. 1992. A sign of generational conflict: The impact of Florida's aging voters on local school and tax referenda. Social Science Quarterly 73:786-797.

Callies, D. L., R. H. Freilich, and T. E. Roberts. 1999. Cases and materials on land use, 4th ed. New York, NY: West Publishing Group.

Campaign for Affordable Housing. 2004. What we know about public attitudes on affordable housing: A review of existing public opinion research. Campaign for Affordable Housing. http:// www.tcah.org/pdf/Public_Attitudes.pdf (accessed July 17, 2006).

Catterall, J. S. 1987. On the social costs of dropping out of school. The High School Journal 71:19-30.

Centers for Disease Control and Prevention. 1997. What every parent should know about lead poisoning in children. http:// www.cdc.gov/nceh/lead/faq/cdc97a.htm (accessed July 16, 2006).

- 1999. Neighborhood safety and the prevalence of physical activity-selected states, 1996. Morbidity and Mortality Weekly Report 47:143-146.

Children's Sentinel Nutrition Program. 2004. The safety net in action. Boston, MA. 
Cohen, D., K. Mason, A. Bedimo, R. Schribner, V. Basolo, and T. A. Farley. 2003. Neighborhood physical conditions and health. American Journal of Public Health 93 (3): 467-71.

Coulton, C., Corbin, J. and M. Su. 1999. Neighborhoods and child maltreatment: A multi-level study. Child Abuse and Neglect 23: 1019-40.

Crowley, S. 2003. The affordable housing crisis: Residential mobility of poor families and school mobility of poor children. Journal of Negro Education 72 (1): 22-38.

Cubbin, C., F. B. LeClere, and G. S. Smith. 2000. Socioeconomic status and injury mortality: Individual and neighborhood determinants. Journal of Epidemiology and Community Health 54:517-524.

Danter Company. 2001. The impact of low income housing tax credit development on a local school district. http://www.danter.com/taxcredit/lihtckids1.htm (accessed June 9, 2005).

Davis, A. F. 1967. Spearheads for reform: The social settlements and the Progressive movement, 1890-1914. New York: Oxford University Press.

Diez Roux, A. V., S. S. Merkin, D. Arnett, L. Chambless, M. Massing, F. Nieto, P. Sorlie, M. Szklo, H., Tyroler, and R. Watson. 2001. Neighborhood of residence and incidence of coronary heart disease. New England Journal of Medicine 345:99-106. Donahue Institute. 2005. Housing poll conducted for the citizens' housing and planning association. University of Massachusetts.

Duncan, G., and J. Ludwig. 2000. Can housing vouchers help poor children? Children's Roundtable Report \#3. Washington, DC: TheBrookings Institution.

Duncombe W., M. Robbins, J. Stonecash. 2003. Measuring citizen preferences for public services using surveys: Does a "gray peril" threaten funding for public education? Public Budgeting and Finance 23 (1): 45-72.

Dunn, J. R. 2000. Housing and health inequalities: Review and prospects for research. Housing Studies 15 (3): 341-366.

Elliott, D., W. Wilson, D. Huizinga, R. Sampson, A. Elliott, and B. Rankin. 1996. The effects of neighborhood disadvantage on adolescent development. Journal of Research on Crime and Delinquency 33:389-426.

Erikson, R. S., and K. L. Tedin. 2003. American public opinion, 6th ed. New York: Longman.

Evans, G. W. H.-Y., E. Chan, N. M. Wells, and H. Saltzman. 2000. Housing quality and mental health. Journal of Consulting and 
Clinical Psychology 68(3):526-30.

Evans, R. 1992. Asthma among minority children: A growing problem. Chest 101S: 368371.

Galster, G., and S. Killen. 1995. The geography of metropolitan opportunity: A reconnaissance and conceptual framework. Housing Policy Debate 6:(1).

Gilens, Martin. 1999. Why Americans hate welfare: Race, media and the politics of antipoverty policy. Chicago: University of Chicago Press.

Goering, J. 2003. The impacts of new neighborhoods on poor families: Evaluating the policy implications of moving to opportunity demonstration. Federal Reserve Bank of New York Economic Policy Review, June.

Goering, J., J. Kraft, J. Feins, D. McInnis, M. J. Holin, and

H. Elhassan. 1999. Moving to opportunity for fair housing demonstration program:

Current status and initial findings. Washington, DC: U.S. Department of Housing and Urban Development.

Hartman, C., and T. M. Franke. 2003. Student mobility: How some children get left behind. Journal of Negro Education 72 (1): 1-5.

Haveman, R., and B. Wolfe. 1994. Succeeding generations: On the effects of investments in children. New York: Russell Sage Foundation.

Haveman, R., B. Wolfe, and J. Spaulding. 1991. Childhood events and circumstances influencing high school completion. Demography 28 (1): 133-157.

Hopton, J., and S. Hunt. 1996. The health effects of improvements to housing: A longitudinal study. Housing Studies 11(2).

House, J., Kessler, R., Herzog, A. Meto, R., Kinney, A., Breslow, M. 1990. Age, socioeconomic status and health. Milbank Quarterly 68: 383-411.

Housing Illinois. 2003. Valuing housing: Public perceptions of affordable housing in the Chicago region. Chicago: Housing Illinois, April.

http://www.bpichicago.org/rah/pubs/housing_ Illinois_report.pdf (accessed January 9, 2007).

Howell, E., Harris, L., and S. Popkin. 2005. The health status of HOPE VI public housing residents. Journal of Health Care for the Poor and Underserved 16(2):273-285.

Humpel, N., Owen, N., and E. Leslie. 2002. Environmental factors associated with adults' participation in physical activity. 
American Journal of Preventive Medicine 22 (3): 188-199.

Inman, R. 1978. Testing political economy's "as if" proposition: Is the median income voter really decisive? Public Choice 33:45-65.

Jencks, C., and S. Mayer. 1990. The social consequences of growing up in a poor neighborhood. In Inner city poverty in the United States, eds. L. Lynn, Jr. and M. McGeary, 111-186. Washington, DC: National Academy Press.

Kain, J. F., and J. M. Quigley. 1970. Measuring the value of housing quality. Journal of the American Statistical Association 65:532-46.

Katz, Lawrence F., Jeffrey R. Kling, and Jeffrey B. Liebman. 2001. Moving to opportunity in Boston: Early results of a randomized mobility experiment. The Quarterly Journal of Economics 116(2).

Kaufman, J., and J. Rosenbaum. 1992. The education and employment of low-income black youth in white suburbs. Educational Evaluation and Policy Analysis 14 (3): 22940.

Kearns, R.A., and Smith, C. J., 1993. Housing stressors and mental health among marginalized urban populations. In 2000 Housing and health inequalities: Review and prospects for research, ed. J. Dunn. Housing Studies 200015 (3): 341-366.

Leventhal, T., and J. Brooks-Gunn. 2000. The neighborhoods they live in: The effects of neighborhood residence on child and adolescent outcomes. Psychological Bulletin 126 (2): 309-37.

Levy, H., and T. DeLeire. 2003. What do people buy when they don't buy health insurance and what does that say about why they are uninsured. NBER Working Paper No. 9826, Cambridge, MA: National Bureau of Economic Research, July.

Li, M. M., and H. J. Brown. 1980. Micro-neighborhood externalities and hedonic housing prices. Land Economics 56:125-41.

Link, B., and J. Phelan. 1995. Social conditions as fundamental causes of disease. Journal of Health and Social Behavior, Extra Issue 80-94.

Lipman, B. J. 2005. Something's gotta give: Working families and the cost of housing. New Century Housing 5(2).

Mallonee, S., G. Istre, M. Rosenberg, M. Reddish-Douglas, F. Jordan, P. Silverstein, and W. Tunell. 1996. Surveillance and prevention of residential fire injuries. New England Journal of Medicine 335:27-31. 
Marcus, C. C. 1995. House as a mirror of self: Exploring the deeper meaning of home. Berkeley, CA: Conari Press.

Marsh, A., D. Gordon, P. Heslop, and C. Pantazis. 2000. Housing deprivation and health: A longitudinal analysis. Housing Studies 15 (3): 411-428.

Massey, D. S., and N. A. Denton. 1993. American apartheid: Segregation and the making of the underclass. Cambridge, MA: Harvard University Press.

Matte, T. D., and D. E. Jacobs. 2000. Housing and health: Current issues and implications for research and programs. Journal of Urban Health 77:7-25.

Molnar, B. E., S. L. Gortmaker, F. C. Bull, and S. L. Buka. 2003. Unsafe to play? Neighborhood disorder and lack of safety predict reduced physical activity among urban children and adolescents. American Journal of Health Promotion 18 (5): 378-386.

National Association of Realtors. 2003. National housing opportunity pulse. September. http://www.realtor.org/PublicAffairsWeb.nsf/files/HousingOpsSurveyResults.pdf/\$FILE/H ousingOpsSurvey- Results.pdf (accessed December 29, 2006).

Nelson, P. S., J. M. Simoni, and H. S. Adelman. 1996. Mobility and school functioning in the early grades. Journal of Education Research 89 (6): 365-369.

O'Campo, P. 2003. Invited commentary: Advancing theory and methods for multilevel models of residential neighborhoods and health. American Journal of Epidemiology 157 (1): 9-13.

Orr, L., J. Feins, R. Jacob, E. Beecroft, L. Sanbonmatsu, L. Katz, J. Leibman, and J. Kling. 2003. Moving to opportunity interim impacts evaluation. (September). Washington, DC: U.S. Department of Housing and Urban Development.

Pearl, M., P. Braverman, and B. Abrams. 2001. The relationship of neighborhood socioeconomic characteristics to birth weight among 5 ethnic groups in California. American Journal of Public Health 91:1808-1814.

Platts-Mills, T., W. Thomas, R. Aalberse, D. Vervloet, and M. Champman. 1992. Dust mite allergens and asthma: Report of the second international workshop. Journal of Allergy and Clinical Immunology 89:1046-1060.

Plautz, B., D. Beck, C. Selmar, and M. Radetsky. 1996. Modifying the environment: A community-based injury-prevention program for elderly residents. American Journal of Preventative Medicine 12:33-38.

Popkin, S., D. Levy, L. Harris, J. Comey, M. Cunningham, and L. Buron. The HOPE VI program: What about the residents? 
Housing Policy Debate 15 (2): 385-414.

Popkin, S., L. Buron, D. Levy, and M. Cunningham. 2000. The Gautreaux legacy: What might mixed income and dispersal strategies mean for the poorest public housing tenants? Housing Policy Debate 11 (4): 911-42.

Poterba, J. 1997. Demographic structure and the political economy of education. Journal of Policy Analysis and Management 16:48-66.

Quercia, R. G., and L. K. Bates. 2002. The neglect of America's housing: Consequences and policy responses. Chapel Hill: University of North Carolina at Chapel Hill. http://govinfo.library.unt.edu/mhc/ papers/quercia.doc (accessed January 9, 2007).

Rosenbaum, J. E. 1991. Black pioneers-do their moves to the suburbs increase economic opportunity for mothers and children? Housing Policy Debate 2 (4): 11791213.

1995. Changing the geography of opportunity by expanding residential choice: lessons from the Gautreaux program. Housing Policy Debate 6 (1): 231-269.

Rosenbaum, J., and S. DeLuca. 2000. Is housing mobility the key to welfare reform? Lessons from Chicago's Gautreaux program. Washington, DC: The Brookings Institution.

Rosenbaum, J., M. Kulieke, and L. Rabinowitz. 1988. White suburban schools' responses to low-income black children: Sources of successes and problems. The Urban Review 20 (1): 28-41.

Rosenbaum J. E., S. J. Popkin, J. E. Kaufman, and J. Rusin. 1991. Social integration of low-income black adults in middle class white suburbs. Social Problems 38 (4): 448-61.

Rubinowitz, L., and J. Rosenbaum. 2000. Crossing the class and color lines: From public housing to white suburbia. Chicago: University of Chicago Press.

Rumberger, R. W. 2003. The causes and consequences of student mobility. The Journal of Negro Education 72 (1): 6-21.

Rumberger, R. W., and K. A Larson. 1998. Student mobility and the increased risk of high school dropout. American Journal of Education 107 (1): 1-35.

Saegert, S., S. Klitzman, N. Freudenberg, J. Cooperman-Mroczek, and S. Nassar. 2003. Healthy housing: A structured review of published evaluations of U.S. interventions to improve health by modifying housing in the United States-1990-2001. American Journal of Public Health 93 (9). 
Sampson, R., J. Morenoff, and F. Earls. 1999. Beyond social capital: Spatial dynamics of collective efficacy for children. American Sociological Review 64:633-60.

Sampson, R. J., S. W. Raudenbusch, and F. Earls. 1997. Neighborhoods and violent crime: A multilevel study of collective efficacy. Science 277:918-924.

Sanborn, P., J. Barrett, J. Connery, K. Byron, and M. Coolidge. 2003. Housing the Commonwealth's school-age children: The implications of multi-family housing development for municipal and school expenditures. Boston, MA: Citizens' Housing and Planning Association.

Schulz, A., D. William, B. Israel, A. Becker, E. Parker, S. James, J. and Jackson. 2000. Unfair treatment, neighborhood effects, and mental health in the Detroit metropolitan area. Journal of Health and Social Behavior 41:314-332.

Schultz, B., D. Pawel, and A. Murphy. 1999. A retrospective examination of in-home educational visits to reduce childhood lead levels. Environmental Resources 80.

Schwartz, A. 2006. Housing policy in the United States: An introduction.New York: Routledge.

Schwartz, A., and K. Tajbakhsh. 2001. Mixed-income housing as social policy: The case for diminished expectations. New York: New School University.

Sharfstein, J., M. Sandel, R. Kahn, and H. Bauchner. 2001. Is child health at risk while families wait for housing vouchers? American

Journal of Public Health 91 (8): 1191.

Shaw, R. 2000. There's no place like home: How America's housing crisis threatens our children. Housing America. http://www.housingamerica.net/body_childrens_study.htm (accessed July 17, 2006).

Shlay, A. B. 1993. Family self-sufficiency and housing. Housing Policy Debate 4(3).

Simpson, G. A. and M. G. Fowler. 1994. Geographic mobility and children's emotional/behavioral adjustment and school functioning.

Pediatrics 93 (2): 303-309.

Small, M., and K. Newman. 2001. Urban poverty after The Truly Disadvantaged: The rediscovery of the family, the neighborhoodand culture. Annual Review of Sociology 27:23-45.

Stivers, C. 1995. Settlement women and bureau men: Constructing a usable past for public administration. Public Administration Review 55 (6): 522-529. 
Swanson, G. A., and B. Schneider. 1999. Students on the move: Residential and educational mobility in America's schools. Sociology of Education 72 (1): 54-67.

Teachman, J. D., K. Paasch, and K. Carver. 1996. Social capital and dropping out of school. Journal of Marriage and Family 58 (3): 773-783.

Temple, J. A. J. and Reynolds. 1997. Predictors and consequences of school mobility for urban black children from low income families. Paper presented at the annual meeting of the American Educational Research Association, San Francisco, CA.

Thomson, H., M. Petticrew, and D. Morrison. 2001. Improving housing, improving health: The potential to develop evidence based healthy housing policy. CEM CenterUniversity of Durham

Third International, Interdisciplinary Evidence-Based Policies and Indicator Systems Conference, July.

Tolnay, S. E., R. M. Adelman, and K. D. Crowder. 2002. Race, regional origin, and residents in northern cities at the beginning of the great migration. American Sociological Review 67 (3): 456-75.

Tucker, C. J., J. Marx, L. and Long. 1998. "Moving on": Residential mobility and children's school lives. Sociology of Education 71 (2): 111-129.

U. S. Census. 2001. Geographical mobility: Population characteristics. March 1999 to March 2000. Current Population Reports, P20- 538.

www.census.gov/prod/2001pubs/p20-538.pdf. (accessed July 17, 2006).

U. S. Department of Education, National Center for Education Statistics. 2004. Digest of Education Statistics. Tables 380 and 381.

http://nces.ed.gov/programs/digest/d04/ch_5.asp. (accessed August 17, 2006).

U. S. General Accounting Office. 1994. Elementary school children: Many change schools frequently, harming their education. Washington, DC: GAO.

Weitzman M, S. Gortmaker, and A. Sobol. 1990. A racial, social and environmental risks for childhood asthma. American Journal of Disabled Children 144:1189-94

Wikstrom, P., and R. Loeber. 2000. Do disadvantaged neighborhoods cause welladjusted children to become adolescent delinquents? Criminology 38:1109-42.

Williams, D. 1990. Socioeconomic differences in health: A review and redirection. Social Psychology Quarterly 50: 81-99.

- 1997. Race and health: Basic questions, emerging directions. Annals of Epidemiology 7:322-33. 
Williams, D., and P. Jackson. 2005. Social sources of racial disparities in health. Health Affairs 24 (2): 325-334.

Wilson, W. J. 1987. The truly disadvantaged: The inner city, the underclass and public policy. Chicago: University of Chicago Press.

Wood, D., N. Halfon, D. Scarlata, P. Newacheck, and S. Nessim. 1993. Impact of family relocation on children's growth, development, school function and behavior. Journal of the American Medical Association 270 (11): 1334-1338.

Young, P. 2001. Housing for children: A case for non-shelter policy drivers in housing assistance. Housing Imaginations. Cardiff, UK: Housing Studies Association. 